\title{
High expression of periostin is dramatically associated with metastatic potential and poor prognosis of patients with osteosarcoma
}

\author{
Fei Hu ${ }^{1 *}$, Wei Wang ${ }^{2}$, Hang-Cheng Zhou ${ }^{3}$ and Xi-Fu Shang ${ }^{1}$
}

\begin{abstract}
Background: Recent studies have found that periostin (PN), as a kind of secreted glycoprotein, is closely related to the metastatic potential and prognosis of many kinds of tumors. This study aimed to examine the expression of PN in patients with osteosarcoma and explore the relationship of PN expression with clinicopathologic factors and prognosis.
\end{abstract}

Methods: PN was detected by histopathological and immunohistochemical methods in 62 cases of osteosarcoma and 62 of osteochondroma. Detailed pathological and clinical data were collected by reviewing medical records.

Results: The results showed that increased PN protein expression was prevalent in osteosarcoma and was significantly associated with pathologic subtype $(P=0.000)$, tumor size $(P=0.016)$ and Enneking stage $(P=0.047)$. Additionally, expression of PN was found to be an independent prognostic factor in osteosarcoma patients. High expression of PN protein is closely correlated to the tumor progression and poor survival of osteosarcoma.

Conclusions: Our data suggest that PN is a promising biomarker for identifying individuals with poor prognostic potential and suggests its possible use as a prognostic marker in patients with osteosarcoma.

Keywords: Periostin, Osteosarcoma, Prognosis, Metastasis

\section{Background}

Osteosarcoma accounts for approximately $20 \%$ of primary malignancies of bone, which is the most common malignant primary bone tumor among children and adolescents [1]. It frequently tends to develop distant metastasis and ultimately results in death, especially in cases of lung metastasis. About 20\% of patients present visible metastases with imaging at diagnosis and a quarter patients have metastases during the course of treatment [2]. However, due to lack of effective and efficient tumor biomarkers for early diagnosis, and that any treatment for relapse is absolutely resistant to the relapsed tumor, the prognosis remains poor and most patients die at the advanced stages. Thus, developing a novel predictor for anticipating the invasive potential and prognosis of osteosarcoma is significantly crucial.

\footnotetext{
* Correspondence: anhuishenghufei@163.com

'Department of Orthopedics, Anhui Provincial Hospital, Anhui Medical University, 17\# Lujiang Road, Hefei 230001, People's Republic of China Full list of author information is available at the end of the article
}

Periostin (PN), a member of the fasciclin domain and also called osteoblast-specific factor 2 (OSF-2), is a disulfidelinked cell adhesion protein that has been shown to be expressed preferentially in the periosteum and periodontal ligaments, acting as a critical regulator for bone and tooth formation and maintenance [3-6]. Recently, accumulating evidence has revealed that $\mathrm{PN}$ is overexpressed in various human cancers including liver, head and neck, neuroblastoma, breast, colon, esophageal, ovary, and so on [7-17]. Furthermore, PN as a promising marker for tumor aggression in different types of human cancer have been identified $[8,10]$. In the past, although many studies have focused on the multiple facets of PN in bone metabolism [18-23], few were reported about the expression of PN in bone-related tumors and its potential clinical significance.

In the present study, we have examined the expression levels of PN in osteosarcoma and analyzed its correlation with clinicopathological characteristics and prognosis. 


\section{Methods}

\section{Patients and tissue samples}

A total of 124 patients (62 cases with osteosarcoma and 62 with osteochondroma) who underwent surgical resection between 2003 and 2010 were selected from the Department of Orthopedics in Anhui Provincial Hospital (China). These patients with osteosarcoma were treated according to the standardized protocol consisting of neoadjuvant chemotherapy (four cycles of methotrexate and cisplatin were administered with a minimum of a 21-day interval between consecutive cycles), followed by appropriate surgical management and postoperative adjuvant chemotherapy. All tissue specimens were formalin-fixed and paraffin-embedded for immunohistochemistry staining. Detailed pathological and clinical data were collected by reviewing medical records, including age and gender, age at diagnosis, tumor size, site of primary disease, histologic subtype, complete blood count, erythrocyte sedimentation rate, alkaline phosphatase, serum albumin, and Enneking stage. A total of 62 patients with osteosarcoma were comprised of 33 males and 29 females, with the mean age of $25 \pm 12$-years-old (range: 6 to 52 years). Two pathologists who were blinded to the clinical information confirmed all histological diagnoses and judged the degree of staining independently.

All patients involved in this study had signed the informed consent. The study protocol conformed to the ethical guidelines of the Declaration of Helsinki. Ethical approval for the use of human subjects was obtained from the research ethics committee of Anhui Medical University.

Follow-up was terminated on 8 August 2013. The mean follow-up was of 36.6 months (range: 25 to 92 months). After surgical resection, all patients were monitored using $\mathrm{X}$-ray as preferential, abdominal ultrasonography, technetium bone scans, chest computed tomography (CT) scans
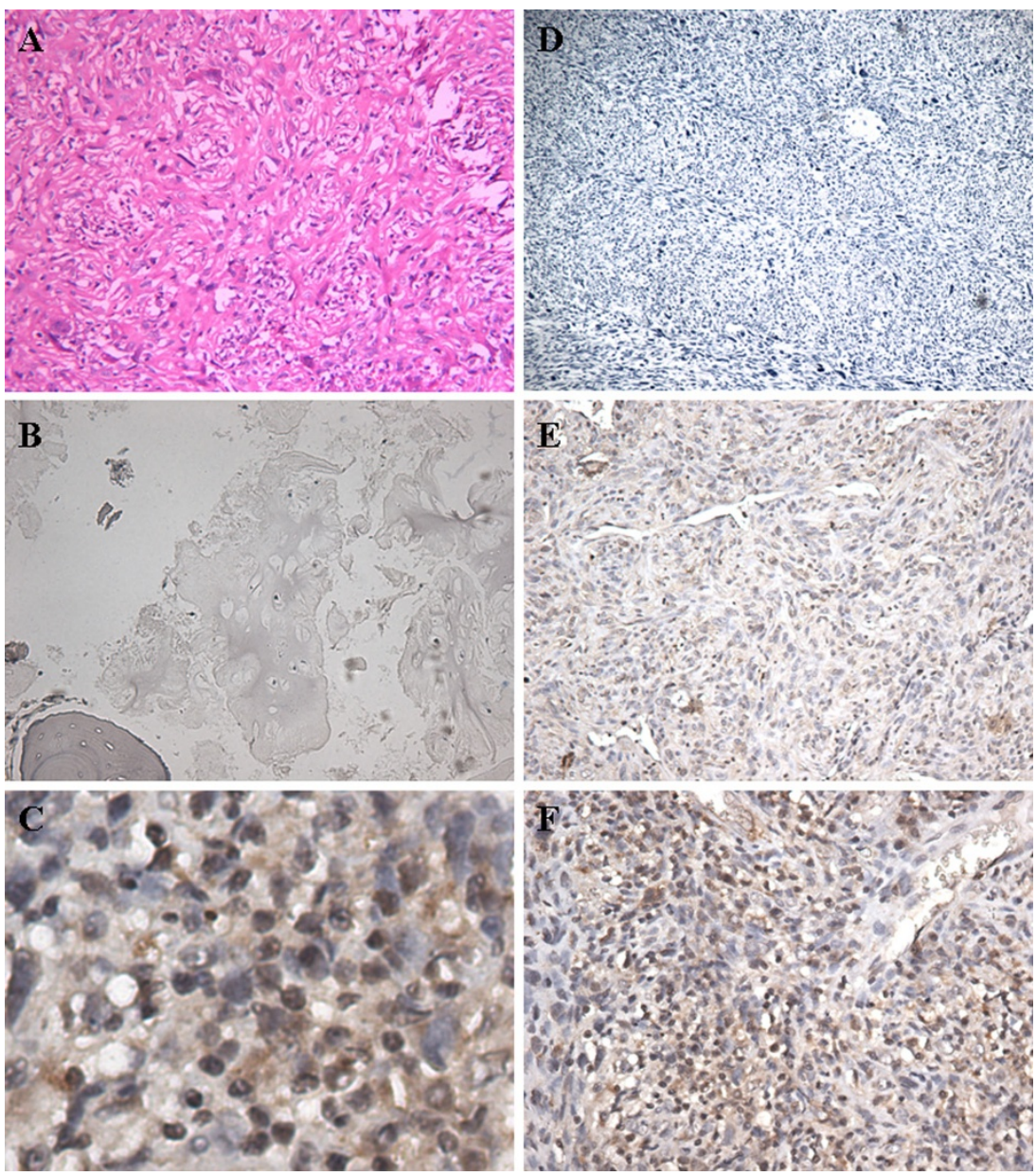

Figure 1 Immunohistochemical staining of periostin in osteosarcoma and osteochondroma tissues. Periostin (PN) mainly expressed in the cytoplasm of osteosarcoma tissues. (A) H\&E staining of osteosarcoma, $\times 100$; (B) negative for PN staining in osteochondroma, $\times 100$; (C) ++ for PN staining in osteosarcoma, $\times 400$; (D) negative for PN staining in osteosarcoma, $\times 40$; (E) + for PN staining in osteosarcoma, $\times 100$; (F) ++ for PN staining in osteosarcoma, $\times 100$. 
Table 1 Differential expression of periostin between osteosarcoma tissues and corresponding osteochondroma (124 cases)

\begin{tabular}{|c|c|c|c|c|}
\hline \multirow[t]{2}{*}{ Tissues } & \multirow{2}{*}{$\begin{array}{c}\text { Case } \\
\text { number }\end{array}$} & \multicolumn{2}{|c|}{ Periostin } & \multirow{2}{*}{$\begin{array}{l}\text { Positive } \\
\text { rate (\%) }\end{array}$} \\
\hline & & Positive & Negative & \\
\hline Osteosarcoma & 62 & 50 & 12 & $80.6 \%$ \\
\hline Osteochondroma & 62 & 11 & 51 & $17.7 \%$ \\
\hline
\end{tabular}

and/or magnetic resonance imaging (MRI) scans every three to six months, prospectively. Overall survival (OS) was defined as the interval between surgery and death or the last observation taken. The data were censored at the last follow-up period for living patients. Relapse-free survival (RFS) was defined as the interval between the date of surgery and the date of diagnosis of any type of relapse or the last follow-up assessment.

\section{Histopathological and immunohistochemical analyses}

Immunohistochemistry was used to examine the expression of PN in all tissue specimens. Rabbit anti-periostin antibody was ordered from Beijing Biosynthesis Biotechnology Co., Ltd (Beijing, China). PV-6000 Power Vision ${ }^{\text {Ts }}$ Two-step histostaining reagent, 3,3-diaminobenzidine tetrahydrochloride (DAB) and phosphate-buffered saline (PBS) were obtained from Beijing Zhongshan Golden Bridge Biotechnology Company (Beijing, China). The whole process was followed by the manufacturer's instructions. Briefly, the tumor

Table 2 Periostin expression status in relation to selected clinicopathologic features in 62 osteosarcoma patients (cases)

\begin{tabular}{|c|c|c|c|c|c|c|c|}
\hline \multirow[t]{2}{*}{ Clinicopathologic data } & \multirow{2}{*}{$\begin{array}{c}\text { Case } \\
\text { number }\end{array}$} & \multicolumn{2}{|c|}{ Periostin } & \multirow[t]{2}{*}{$x^{2}$} & \multirow[t]{2}{*}{$P$ value } & \multirow[t]{2}{*}{ OR } & \multirow[t]{2}{*}{$95 \% \mathrm{Cl}$} \\
\hline & & Positive & $\overline{\text { Negative }}$ & & & & \\
\hline \multicolumn{8}{|l|}{ Sex } \\
\hline Male & 33 & 26 & 7 & 0.156 & 0.693 & 0.774 & $0.216 \sim 2.768$ \\
\hline Female & 29 & 24 & 5 & & & & \\
\hline \multicolumn{8}{|l|}{ Age at diagnosis (years) } \\
\hline$<30$ & 42 & 34 & 8 & 0.008 & 0.929 & 0.941 & $0.247 \sim 3.592$ \\
\hline$>30$ & 20 & 16 & 4 & & & & \\
\hline \multicolumn{8}{|l|}{ Site of primary disease } \\
\hline Tibia & 26 & 22 & 4 & 0.995 & 0.802 & & \\
\hline Femur & 16 & 13 & 3 & & & & \\
\hline Humerus & 10 & 7 & 3 & & & & \\
\hline Other & 10 & 8 & 2 & & & & \\
\hline \multicolumn{8}{|l|}{ Histologic subtype } \\
\hline Special & 5 & 0 & 5 & 22.661 & 0.000 & 8.143 & $4.069 \sim 16.297$ \\
\hline conventional & 57 & 50 & 7 & & & & \\
\hline \multicolumn{8}{|l|}{ Enneking stage } \\
\hline I, II & 49 & 37 & 12 & 3.948 & 0.047 & 1.324 & $1.129 \sim 1.553$ \\
\hline III & 13 & 13 & 0 & & & & \\
\hline \multicolumn{8}{|l|}{ Size (at diagnosis) $(\mathrm{cm})$} \\
\hline$<5$ & 38 & 27 & 11 & 5.787 & 0.016 & 9.370 & $1.123 \sim 78.169$ \\
\hline$>5$ & 24 & 23 & 1 & & & & \\
\hline \multicolumn{8}{|l|}{ Alkaline phosphatase $(\mathrm{u} / \mathrm{L})$} \\
\hline$<500$ & 35 & 28 & 7 & 0.021 & 0.884 & 0.909 & $0.254 \sim 3.258$ \\
\hline$>500$ & 27 & 22 & 5 & & & & \\
\hline \multicolumn{8}{|l|}{ Serum albumin $(g / L)$} \\
\hline$<30$ & 22 & 18 & 4 & 0.03 & 0.862 & 0.889 & $0.235 \sim 3.367$ \\
\hline$>30$ & 40 & 32 & 8 & & & & \\
\hline \multicolumn{8}{|l|}{$\mathrm{ESR}(\mathrm{mm} / \mathrm{hr})$} \\
\hline$<30$ & 45 & 36 & 9 & 0.044 & 0.834 & 0.857 & $0.202 \sim 3.636$ \\
\hline$>30$ & 17 & 14 & 3 & & & & \\
\hline
\end{tabular}

Cl: Confidence interval; ESR: erythrocyte sedimentation rate; OR: the odds ratio; PN: Periostin.

$P<0.05$ was considered to be statistically significant. 
tissues were fixed in $10 \%$ formalin, embedded in paraffin and cut into 4- $\mu$ m-thick sections. The sections were stained with hematoxylin and eosin (HE) for histological examination. The tissue sections were deparaffinized and rehydrated in a graded series of alcohols. The sections were microwaved in citrate buffer ( $\mathrm{pH}$ 6.0) for 20 minutes and then cooled for an additional 20 minutes at room temperature. Endogenous peroxidase activity was blocked with $3 \%$ hydrogen peroxide for 10 minutes. The sections were then immunostained with PN antibody (1:50) (Zhongshan Jinqiao Co., Beijing, China) and incubated at $4^{\circ} \mathrm{C}$ overnight. After rinsing with PBS three times for $5 \mathrm{mi}-$ nutes each, the sections were incubated in horseradish peroxidase-conjugated secondary antibody (Zhongshan Jinqiao Co., Beijing, China) for 20 minutes. After being washed again, peroxidase activity was visualized with $\mathrm{DAB}$ as a chromogen. Sections were counterstained with hematoxylin, dehydrated and mounted. The negative controls were processed in a similar manner with PBS instead of primary antibody. The result of immunohistochemistry was expressed by the staining cells on a graduated percentage (0 to $100 \%$ ). Staining of under $10 \%$ of the tumor cells showed weak or focal immunopositivity or no staining was clarified as negative, staining of 10 to $30 \%$ of tumor cells showed moderate or patchy immunopositivity as + , and staining of over $30 \%$ of tumor cells showed strong or diffuse immunopositivity as ++. A total of 10 fields were selected, and expression in 1,000 tumor cells
(100 cells/field) was evaluated using a high-power $(400 \times)$ microscope [9].

\section{Statistical analysis}

All statistical analyses were performed using SPSS 13.0 (SPSS Inc., Chicago, Illinois, United States). $X^{2}$ and Fisher's exact test was performed to assess associations between PN expression and clinicopathological parameters. The Kaplan-Meier method was used for survival analysis, and differences in survival were estimated using the log-rank test. A multivariate survival analysis was performed for all parameters that were significant in the univariate analysis using the Cox regression model. $P<0.05$ was considered to be statistically significant.

\section{Results}

Immunohistochemical expression of periostin in osteosarcoma and osteochondroma

Immunohistochemical analysis revealed that the positive expression of PN was mainly localized in the cytoplasm, with some tumor cells stained strongly, while others exhibited little or no staining at all (Figure 1). The positive rates of PN in osteosarcoma tissues were $80.6 \%$ (50 out of 62 ) and $17.7 \%$ in osteochondroma (11 out of 62 ), and PN expression in osteochondroma was significantly lower than that in osteosarcoma tissues (Table $1, P<0.05$ ).

To elucidate its clinical significance we evaluated the association between PN expression and clinicopathological
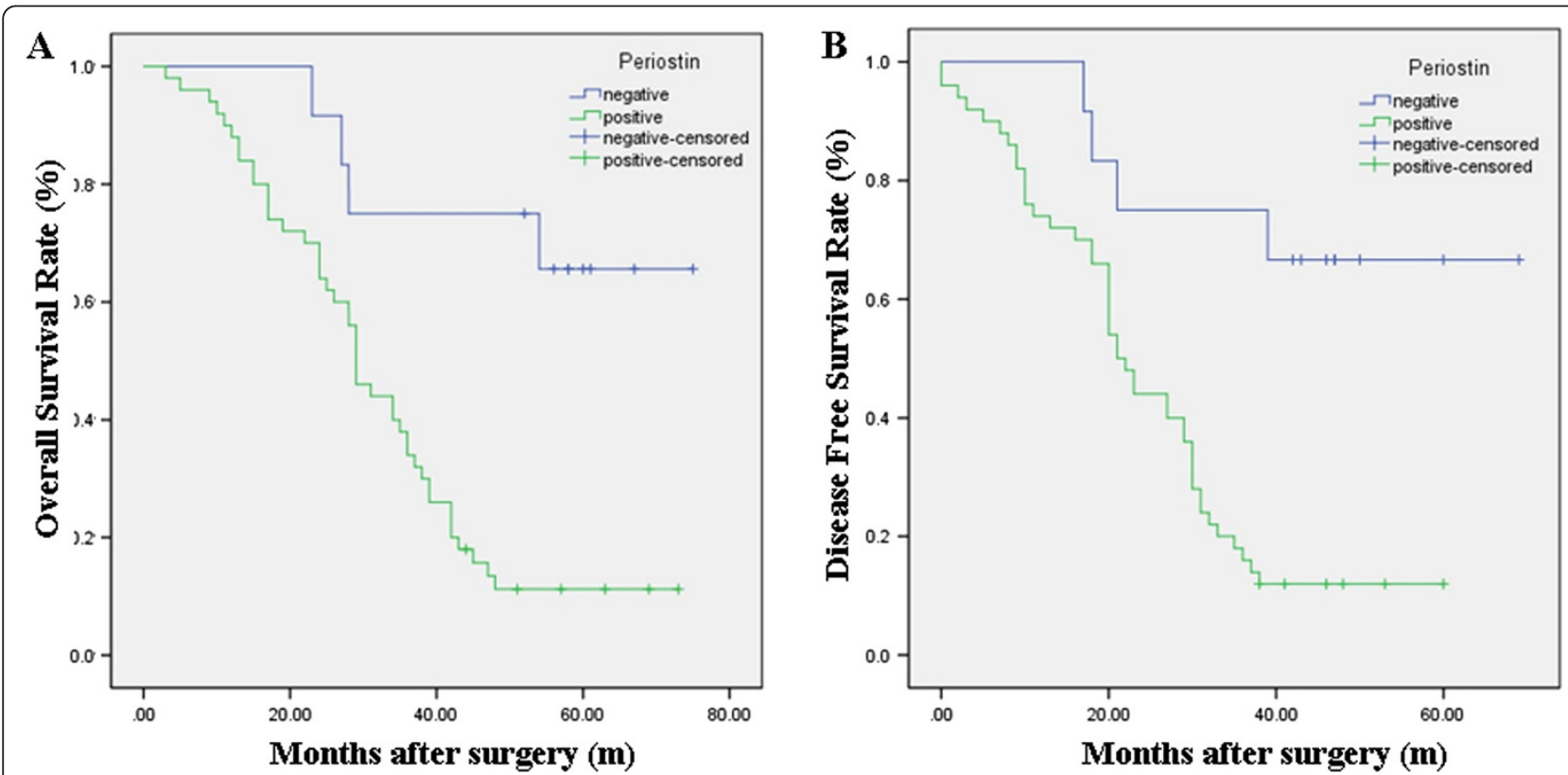

Figure 2 Kaplan-Meier analysis of overall survival (OS) and disease-free survival (DFS) curves of patients with osteosarcoma based on periostin expression as positive or negative. (A) OS curve of patients with osteosarcoma based on periostin expression; (B) DFS curve of patients with osteosarcoma based on periostin expression. The osteosarcoma patients with periostin-positive expression showed significantly poorer OS and DFS rates than those with periostin-negative expression. 
characteristics, including age, sex, location, pathologic subtype, tumor size, Enneking stage, alkaline phosphatase, serum albumin and erythrocyte sedimentation rate (ESR). A detailed histological subtype showed 57 cases of conventional osteosarcoma, 5 cases of special osteosarcoma (including 4 cases of low-grade central osteosarcoma) and 1 case of parosteal osteosarcoma. As shown in Table 2, the expression level of $\mathrm{PN}$ was associated with pathologic subtype $(P=0.000$, odds ratio $(\mathrm{OR})=8.143)$, tumor size $(P=0.016, \mathrm{OR}=9.370)$ and Enneking stage $(P=0.047$,
$\mathrm{OR}=1.324)$, but there was no significant correlation with age, gender, location, alkaline phosphatase level, serum albumin level and ESR.

\section{Relationship between PN expression and prognosis in osteosarcoma}

Patients with PN-positive expression showed a poorer prognosis than those with $\mathrm{PN}$-negative expression by the Kaplan-Meier analysis. The log-rank test revealed that the overall survival time of osteosarcoma patients with PN-

Table 3 Univariate analysis of factors associated with OS and DFS

\begin{tabular}{|c|c|c|c|c|c|c|}
\hline \multirow[t]{2}{*}{ Variable } & \multicolumn{3}{|c|}{ OS } & \multicolumn{3}{|c|}{ DFS } \\
\hline & Mean survival month & $95 \% \mathrm{Cl}$ & $P$ value & Mean survival month & $95 \% \mathrm{Cl}$ & $P$ value \\
\hline \multicolumn{7}{|l|}{ Periostin } \\
\hline Negative & 51 & $42.191-60.975$ & 0.003 & 42 & $32.503-50.663$ & 0.001 \\
\hline Positive & 31 & $26.533-35.347$ & & 23 & $19.578-29.222$ & \\
\hline \multicolumn{7}{|l|}{ Sex } \\
\hline Male & 34 & $30.480-39.391$ & 0.073 & 26 & $22.971-30.868$ & 0.066 \\
\hline Female & 31 & 25.388-36.612 & & 23 & $16.055-29.945$ & \\
\hline \multicolumn{7}{|c|}{ Age at diagnosis (years) } \\
\hline$<30$ & 35 & $30.480-39.391$ & 0.169 & 26 & $22.971-30.868$ & 0.169 \\
\hline$>30$ & 31 & 25.388-36.612 & & 23 & $16.055-29.945$ & \\
\hline \multicolumn{7}{|c|}{ Site of primary disease } \\
\hline Tibia & 31 & 25.388-36.612 & 0.172 & 26 & $22.971-30.868$ & 0.176 \\
\hline Femur & 31 & $25.042-38.833$ & & 25 & $18.766-31.234$ & \\
\hline Humerus & 35 & $19.171-53.424$ & & 28 & $12.358-42.842$ & \\
\hline Other & 41 & $36.846-45.617$ & & 32 & $28.577-35.500$ & \\
\hline \multicolumn{7}{|c|}{ Histologic subtype (n) } \\
\hline Special & 67 & $60.383-74.817$ & 0.000 & 56 & $46.412-65.988$ & 0.000 \\
\hline Conventional & 32 & 28.044-36.096 & & 24 & $20.849-27.852$ & \\
\hline \multicolumn{7}{|l|}{ Enneking stage } \\
\hline I, II & 40 & $35.700-44.668$ & 0.000 & 31 & $27.668-35.556$ & 0.000 \\
\hline III & 15 & $10.727-19.580$ & & 9 & 5.144-13.318 & \\
\hline \multicolumn{7}{|c|}{ Size (at diagnosis) (cm) } \\
\hline$<5$ & 44 & $39.965-49.193$ & 0.000 & 35 & $31.469-39.636$ & 0.000 \\
\hline$>5$ & 19 & $15.395-23.938$ & & 13 & $9.586-16.914$ & \\
\hline \multicolumn{7}{|c|}{ Alkaline phosphatase (u/L) } \\
\hline$<500$ & 33 & $30.480-38.391$ & 0.162 & 26 & 22.971-30.868 & 0.151 \\
\hline$>500$ & 31 & $25.388-36.612$ & & 23 & $16.055-29.945$ & \\
\hline \multicolumn{7}{|c|}{ Serum albumin (g/L) } \\
\hline$<30$ & 35 & $31.224-39.031$ & 0.211 & 27 & $22.845-31.547$ & 0.278 \\
\hline$>30$ & 31 & $25.308-35.578$ & & 24 & $18.454-28.567$ & \\
\hline \multicolumn{7}{|l|}{ ESR $(\mathrm{mm} / \mathrm{hr})$} \\
\hline$<30$ & 34 & $31.135-39.023$ & 0.060 & 26 & $21.975-30.086$ & 0.126 \\
\hline$>30$ & 31 & $25.886-34.479$ & & 23 & 19.333-28.792 & \\
\hline
\end{tabular}

Cl: Confidence interval; DFS: disease free survival; ESR: erythrocyte sedimentation rate; OS: Overall survival; $P<0.05$ was considered to be statistically significant. 

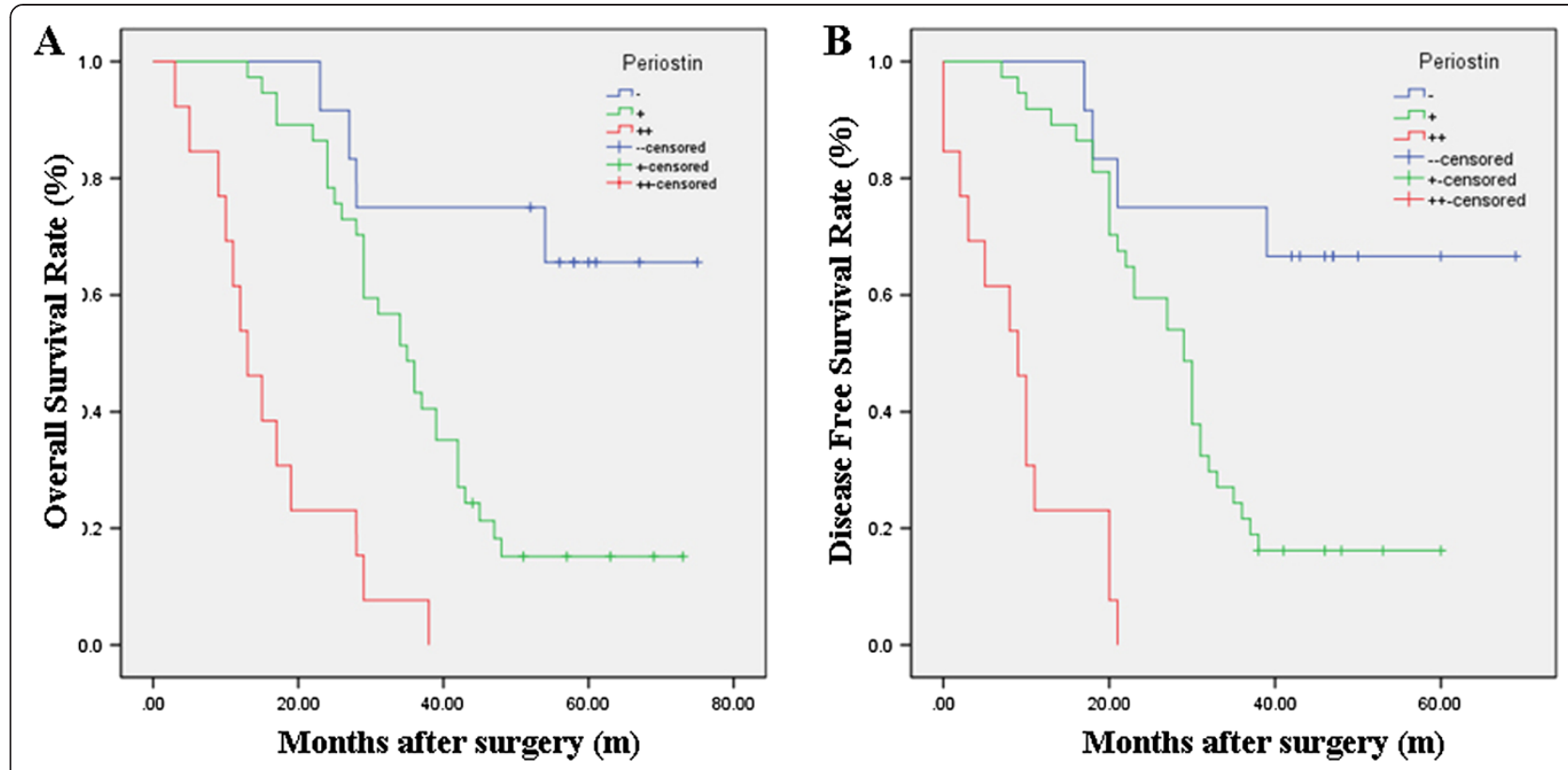

Figure 3 Kaplan-Meier analysis of overall survival (OS) and disease-free survival (DFS) curves of patients with osteosarcoma based on periostin expression as strongly positive, weakly positive or negative. (A) OS curve of patients with osteosarcoma based on periostin expression; (B) DFS curve of patients with osteosarcoma based on periostin expression. The osteosarcoma patients with periostin-positive expression showed significantly poorer OS and DFS rates than those with periostin-negative expression. The survival of patients in the strongly positive periostin expression was poorest.

positive expression was markedly shorter than that with PN-negative expression $(P=0.003$; Figure 2A; Table 3$)$. Furthermore, similar results were also observed in the disease-free survival analysis $(P=0.001$; Figure $2 \mathrm{~B}$; Table 3$)$. To understand deeply about the relationship between the PN-positive expression and prognosis, two different degrees of positive expression were analyzed using the Kaplan-Meier method (Figure 3). Moreover, as seen in Table 4, multivariate Cox analysis indicated that PN expression was one of the independent prognostic factors, along with pathologic subtype, Enneking stage and tumor size. At the last follow-up appointment, 44 patients in the PN-positive groups had died, with a median survival time of 31 months. Of these, two patients developed local recurrence and three had lung metastasis. Comparatively, six patients died in the PN-negative groups and the median survival time was 51 months.

\section{Discussion}

Periostin, originally named as osteoblast-specific factor-2 (OSF-2) and first identified in bone, has been implicated in regulating adhesion and differentiation of osteoblasts [3-5]. The molecular structure of $\mathrm{PN}$ is particularly highly homologous to ßig-h3, which promotes cell adhesion and the spreading of fibroblasts [3]. By RNA dot-blot analysis, PN expression was observed in a wide range of normal adult tissues, including aorta, stomach, lower gastrointestinal tract, placenta, uterus and breast [24]. Recently, it has been frequently reported that PN is overexpressed in various types of human malignant tumors. For instance, Kudo et al. [9] reported PN was overexpressed in oral cancer cells and enhanced migration and invasion. Furthermore, in vitro studies such as Bao et al. [14], demonstrated that highly vascular metastatic tumors derived from the periostin-producing cells showed fewer apoptotic

Table 4 Multivariate analysis of factors associated with OS and DFS

\begin{tabular}{|c|c|c|c|c|c|c|}
\hline \multirow[t]{2}{*}{ Variable } & \multicolumn{3}{|c|}{ OS } & \multicolumn{3}{|c|}{ DFS } \\
\hline & Hazard ratio & $95 \% \mathrm{Cl}$ & $P$ value & Hazard ratio & $95 \% \mathrm{Cl}$ & $P$ value \\
\hline Periostin (Negative versus positive) & 3.751 & $1.564-8.367$ & 0.001 & 3.403 & $1.644-7.908$ & 0.001 \\
\hline Pathologic subtype (Conventional versus special) & 2.434 & $1.275-4.564$ & 0.003 & 2.822 & $1.577-5.057$ & 0.001 \\
\hline Enneking stage (I, II versus III) & 3.156 & $1.788-5.693$ & 0.000 & 3.172 & $1.809-5.629$ & 0.000 \\
\hline Tumor size, $\mathrm{cm}(\leq 5$ versus $>5)$ & 2.039 & $1.108-3.784$ & 0.021 & 2.024 & $1.137-3.70$ & 0.018 \\
\hline
\end{tabular}

$\mathrm{Cl}$ : Confidence interval; DFS: disease free survival; OS: Overall survival. $\mathrm{P}<0.05$ was considered statistically significant. 
cells than control cells. Accumulated findings indicated that overexpression of PN might be common in tumor development. However, some authors have reported that downregulation of PN mRNA was significantly related to higher grade bladder cancer [25,26]. Furthermore, Kanno et al. [27] have demonstrated that PN has biphasic effects on the migration of pancreatic carcinoma. These varied findings suggest that PN might have different functions for different pathological types of cancer. However, PN expression status and the relation with prognosis in osteosarcoma have not been clearly explained until now.

Osteosarcoma is the most common malignant primary bone tumor with a high capacity for distant metastasis. Although the survival rate for patients with osteosarcoma has significantly improved over the past two decades through the use of a combination of aggressive chemotherapy and surgery, metastatic or recurrent disease still occurs in 30 to $40 \%$ of these patients and the majority of those succumb to the disease [28]. Therefore, it is critical to identify the tumor metastasis-associated biomarkers of osteosarcoma. In the present study, we discovered that the PN expression in tumor tissues of patients with osteosarcoma was significantly increased compared with those with osteochondroma. Furthermore, we found that osteosarcoma with PN-positive expression were more frequently Enneking stage III, with a tumor size $>5 \mathrm{~cm}$, and a conventional pathologic subtype than osteosarcoma with $\mathrm{PN}$ negative expression. Accumulated findings indicated that OS and DFS were better in patients without PN expression than those in patients with $\mathrm{PN}$-positive expression. Both Kaplan-Meier and multivariate analysis showed that the expression of PN was an independent predictor of poor prognosis for both OS and DFS. The relationship between PN staining intensity and patient survival was also analyzed, and a general inverse trend between a decline in patient survival and an increase in PN staining intensity was observed. As observed in other cancers, increased expression of PN was associated with cell proliferation, adhesion, and migration. These results indicated that $\mathrm{PN}$ expression had an adverse influence on the osteosarcoma outcome. PN may be used as a marker to predict osteosarcoma patients' prognosis.

A major limitation of this single-center study is its relatively small sample size. Secondly, the underlying molecular mechanisms are not been explored in this study. Recently, some studies revealed that PN binding to the integrins activates the focal adhesion kinase (FAK)- and

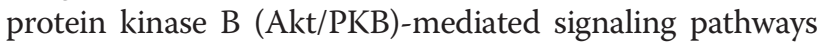
which promote tumor angiogenesis, invasion, and metastasis $[29,30]$. On the other hand, Windischhofer et al. [31] demonstrated that PN was abundantly expressed in human MG-63 osteosarcoma cells. Stimulation of cells with Lysophosphatidic acid (LPA) resulted in a decrease of PN that was strictly dependent on early growth response-1
(Egr-1) expression levels mediated strictly via the Goi/ Src/p42/44 MAPK(mitogen-activated protein kinases) pathway with no involvement of the Goq/11/PLC/PKC (phospholipase C, protein kinase C) or the PLD (phospholipase D)/PI3 kinase/Akt pathways. Thus, to illuminate these findings, further investigations will still be required to explore its exact mechanisms.

\section{Conclusions}

In conclusion, our study found that PN expression was higher in osteosarcoma tissues compared with osteochondroma tissues and its overexpression was closely correlated with Enneking stage, tumor size, and pathologic subtype. Taken together, these preliminary results suggest that the overexpression of PN is a potential prognostic factor for osteosarcoma development and progression. In future, if this activity could be blocked by some specific inhibitors, it could provide a new target for the treatment of osteosarcoma.

\section{Abbreviations}

DAB: 3,3-diaminobenzidine tetrahydrochloride; Egr-1: early growth response-1; FAK: focal adhesion kinase; HE: Hematoxylin and eosin; LPA: Lysophosphatidic acid; MAPK: mitogen-activated protein kinases; OS: Overall survival; OSF-2: Osteoblast-specific factor 2; PBS: Phosphate-buffered saline; PKB: protein kinase B; PKC: phospholipase C; PLD: phospholipase D; PLC: phospholipase C; PN: Periostin; RFS: Relapse-free survival.

\section{Competing interests}

The authors declare that they have no competing interests.

\section{Authors' contributions}

FH participated in the study design, analyzed the data, and prepared the manuscript. WW contributed part of the experiment, research design. FH and WW contributed equally to this work as co-first authors. HCZ collected the tissues and performed the immunohistochemistry. XFS oversaw the design of the study. All authors read and approved the final manuscript.

\section{Acknowledgements}

This research was partly supported by the National Natural Science Foundation of China (grant number: 81201906).

\section{Author details}

'Department of Orthopedics, Anhui Provincial Hospital, Anhui Medical University, 17\# Lujiang Road, Hefei 230001, People's Republic of China ${ }^{2}$ Department of Medical Oncology, Anhui Provincial Hospital, Anhui Medical University, 17\# Lujiang Road, Hefei 230001, People's Republic of China. ${ }^{3}$ Department of Pathology, Anhui Provincial Hospital, Anhui Medical University, 17\# Lujiang Road, Hefei 230001, People's Republic of China.

Received: 23 July 2014 Accepted: 2 September 2014 Published: 15 September 2014

\section{References}

1. Arndt CA, Crist WM: Common musculoskeletal tumors of childhood and adolescence. N Engl J Med 1999, 341:342-352

2. Théoleyre S, Mori K, Cherrier B, Passuti N, Gouin F, Rédini F, Heymann D: Phenotypic and functional analysis of lymphocytes infiltrating osteolytic tumors: use as a possible therapeutic approach of osteosarcoma. BMC Cancer 2005, 27:123.

3. Litvin J, Selim AH, Montgomery MO, Lehmann K, Rico MC, Devlin H, Bednarik DP, Safadi FF: Expression and function of periostin-isoforms in bone. J Cell Biochem 2004, 92:1044-1061. 
4. Zhu S, Barbe MF, Amin N, Rani S, Popoff SN, Safadi FF, Litvin J: Immunolocalization of Periostin-like factor and Periostin during embryogenesis. J Histochem Cytochem 2008, 56:329-345.

5. Horiuchi K, Amizuka N, Takeshita S, Takamatsu H, Katsuura M, Ozawa H, Toyama Y, Bonewald LF, Kudo A: Identification and characterization of a novel protein, periostin, with restricted expression to periosteum and periodontal ligament and increased expression by transforming growth factor beta. J Bone Miner Res 1999, 14:1239-1249.

6. Takeshita S, Kikuno R, Tezuka K, Amann E: Osteoblast-specific factor 2: cloning of a putative bone adhesion protein with homology with the insect protein fasciclin I. Biochem J 1993, 294:271-278.

7. Ismail RS, Baldwin RL, Fang J, Browning D, Karlan BY, Gasson JC, Chang DD: Differential gene expression between normal and tumor-derived ovarian epithelial cells. Cancer Res 2000, 60:6744-6749.

8. Siriwardena BS, Kudo Y, Ogawa I, Kitagawa M, Kitajima S, Hatano H, Tilakaratne WM, Miyauchi M, Takata T: Periostin is frequently overexpressed and enhances invasion and angiogenesis in oral cancer. Br J Cancer 2006, 95:1396-1403.

9. Kudo Y, Ogawa I, Kitajima S, Kitagawa M, Kawai H, Gaffney PM, Miyauchi M, Takata T: Periostin promotes invasion and anchorage-independent growth in the metastatic process of head and neck cancer. Cancer Res 2006, 66:6928-6935.

10. Chang Y, Lee TC, Li JC, Lai TL, Chua HH, Chen CL, Doong SL, Chou CK Sheen TS, Tsai CH: Differential expression of osteoblast-specific factor 2 and polymeric immunoglobulin receptor genes in nasopharyngeal carcinoma. Head Neck 2005, 27:873-882.

11. Fluge $O$, Bruland $O$, Akslen LA, Lillehaug JR, Varhaug JE: Gene expression in poorly differentiated papillary thyroid carcinomas. Thyroid 2006, 16:161-175.

12. Sasaki H, Sato $Y$, Kondo S, Fukai I, Kiriyama M, Yamakawa $Y$, Fuji $Y$ : Expression of the periostin mRNA level in neuroblastoma. J Pediatr Surg 2002, 37:1293-1297.

13. Shao R, Bao S, Bai X, Blanchette C, Anderson RM, Dang T, Gishizky ML, Marks JR, Wang XF: Acquired expression of periostin by human breast cancers promotes tumor angiogenesis through up-regulation of vascular endothelial growth factor receptor 2 expression. Mol Cell Biol 2004 24:3992-4003

14. Bao S, Ouyang G, Bai X, Huang Z, Ma C, Liu M, Shao R, Anderson RM, Rich JN, Wang XF: Periostin potently promotes metastatic growth of colon cancer by augmenting cell survival via the Akt/PKB pathway. Cancer Cell 2004, 5:329-339.

15. Lv Y, Wang W, Jia WD, Sun QK, Li JS, Ma JL, Liu WB, Zhou HC, Ge YS, Yu JH, $\mathrm{Xia} \mathrm{HH}, \mathrm{Xu} \mathrm{GL}$ : High-level expression of periostin is closely related to metastatic potential and poor prognosis of hepatocellular carcinoma. Med Oncol 2013, 30:385.

16. Lv Y, Wang W, Jia WD, Sun QK, Huang M, Zhou HC, Xia HH, Liu WB, Chen H, Sun $\mathrm{SN}, \mathrm{Xu} \mathrm{GL}$ : High preoperative levels of serum periostin are associated with poor prognosis in patients with hepatocellular carcinoma after hepatectomy. Eur J Surg Oncol 2013, 39:1129-1135.

17. Wang W, Sun QK, He YF, Ma DC, Xie MR, Ji CS, Hu B: Overexpression of periostin is significantly correlated to the tumor angiogenesis and poor prognosis in patients with esophageal squamous cell carcinoma. Int $\mathrm{J}$ Clin Exp Pathol 2014, 7:593-601.

18. Dwek JR: The periosteum: what is it, where is it, and what mimics it in its absence? Skeletal Radiol 2010, 39:319-323.

19. Ogita M, Rached MT, Dworakowski E, Bilezikian JP, Kousteni S: Differentiation and proliferation of periosteal osteoblast progenitors are differentially regulated by estrogens and intermittent parathyroid hormone administration. Endocrinology 2008, 149:5713-5723.

20. Kashima TG, Nishiyama T, Shimazu K, Shimazaki M, Kii I, Grigoriadis AE, Fukayama M, Kudo A: Periostin, a novel marker of intramembranous ossification, is expressed in fibrous dysplasia and in c-Fos-overexpressing bone lesions. Hum Pathol 2009, 40:226-237.

21. Rani S, Barbe MF, Barr AE, Litvin J: Periostin-like-factor and periostin in an animal model of work-related musculoskeletal disorder. Bone 2009 44:502-512

22. Kasperkovitz PV, Timmer TC, Smeets TJ, Verbeet NL, Tak PP, van Baarsen LG, Baltus B, Huizinga TW, Pieterman E, Fero M, Firestein GS, van der Pouw Kraan TC, Verweij CL: Fibroblast-like synoviocytes derived from patients with rheumatoid arthritis show the imprint of synovial tissue heterogeneity: evidence of a link between an increased myofibroblast-like phenotype and high-inflammation synovitis. Arthritis Rheum 2005, 52:430-441.

23. Geyer M, Grassel S, Straub RH, Schett G, Dinser R, Grifka J, Gay S, Neumann E, Muller-Ladner U: Differential transcriptome analysis of intraarticular lesional vs intact cartilage reveals new candidate genes in osteoarthritis pathophysiology. Osteoarthr Cartil 2009, 17:328-335.

24. Gillan L, Matei D, Fishman DA, Gerbin CS, Karlan BY, Chang DD: Periostin secreted by epithelial ovarian carcinoma is a ligand for alpha(V)beta(3) and alpha(V)beta(5) integrins and promotes cell motility. Cancer Res 2002, 62:5358-5364.

25. Kim CJ, Yoshioka N, Tambe Y, Kushima R, Okada Y, Inoue H: Periostin is down-regulated in high grade human bladder cancers and suppresses in vitro cell invasiveness and in vivo metastasis of cancer cells. Int $J$ Cancer 2005, 117:51-58.

26. Kim CJ, Isono T, Tambe Y, Chano T, Okabe H, Okada Y, Inoue H: Role of alternative splicing of periostin in human bladder carcinogenesis. Int J Oncol 2008, 32:161-169.

27. Kanno A, Satoh K, Masamune A, Hirota M, Kimura K, Umino J, Hamada S, Satoh A, Egawa S, Motoi F, Unno M, Shimosegawa T: Periostin, secreted from stromal cells, has biphasic effect on cell migration and correlates with the epithelial to mesenchymal transition of human pancreatic cancer cells. Int J Cancer 2008, 122:2707-2718.

28. Yang W, Maolin H, Jinmin Z, Zhe W: High expression of metabotropic glutamate receptor 4: correlation with clinicopathologic characteristics and prognosis of osteosarcoma. J Cancer Res Clin Oncol 2014, 140:419-426.

29. Li G, Jin R, Norris RA, Zhang L, Yu S, Wu F, Markwald RR, Nanda A, Conway SJ, Smyth SS, Granger DN: Periostin mediates vascular smooth muscle cell migration through the integrins alphavbeta3 and alphavbeta5 and focal adhesion kinase (FAK) pathway. Atherosclerosis 2010, 208:358-365.

30. Utispan K, Sonongbua J, Thuwajit P, Chau-In S, Pairojkul C, Wongkham S, Thuwajit C: Periostin activates integrin alpha5beta1 through a PI3K/ AKTdependent pathway in invasion of cholangiocarcinoma. Int $J$ Oncol 2012, 41:1110-1118.

31. Windischhofer W, Huber E, Rossmann C, Semlitsch M, Kitz K, Rauh A, Devaney $T$, Leis HJ, Malle E: LPA-induced suppression of periostin in human osteosarcoma cells is mediated by the LPA(1)/Egr-1 axis. Biochimie 2012, 94:1997-2005.

doi:10.1186/1477-7819-12-287

Cite this article as: Hu et al:: High expression of periostin is dramatically associated with metastatic potential and poor prognosis of patients with osteosarcoma. World Journal of Surgical Oncology 2014 12:287.

\section{Submit your next manuscript to BioMed Central and take full advantage of:}

- Convenient online submission

- Thorough peer review

- No space constraints or color figure charges

- Immediate publication on acceptance

- Inclusion in PubMed, CAS, Scopus and Google Scholar

- Research which is freely available for redistribution
C) Biomed Central 